Journal of

Accident and

Emergency

Medicine 1994

11, $121-124$

\title{
Farm accidents involving power take-off devices
}

\author{
P. HYLAND-MCGUIRE
}

Faculty of Medicine and Health Sciences, United Arab Emirates University, Al Ain, United Arab Emirates

\section{INTRODUCTION}

Agricultural trauma is an important cause of mortality and significant permanent disability. An occupational fatality rate ${ }^{1}$ of 21 deaths per 100000 agricultural workers per year was reported in the United States by the National Institute for Occupational Safety and Health. This contrasted with an average of 7.8 deaths per 100000 workers for all occupations combined. A survey ${ }^{2}$ conducted in an Irish county with a population of 52379 , recorded 17 deaths during a 10-year period from 1977 to 1987. In addition, 150 non-fatal farm accidents were recorded during 1986 in the same geographical area. Significantly, fewer than three deaths in the series were beyond the control of the deceased or their guardians and many of the non-fatal incidents were associated with risk taking by the victim. During a 12-year period, of 739 patients admitted to a Wisconsin ${ }^{3}$ referral Trauma Centre with injuries incurred whilst farming, the injury mechanisms in $7 \%$ of cases involved a power take-off (PTO) shaft. Illustrative of the severity of this injury was the fact that three of the 16 deaths in the series occurred as a result of this device. State of Wisconsin statistics for fatal farm injuries from 1985 to 1989 ranked tractor roll-overs, PTO accidents and falls as the most common cause of death. ${ }^{3}$ Of the 47 accidents involving a PTO device in the Wisconsin ${ }^{3}$ trial, 32 resulted in upper limb trauma; there were six major amputations; 10 patients sustained serious injury to the branchial plexus and peripheral nerves; one patient had a severe degloving urogenital injury; and there were 3 near-strangulations. Additionally 20 patients had residual significant permanent disability. In this paper, five case summaries of PTO injuries collected from the admissions to two West Dublin City hospitals over a 2-year period are presented and the injury precipitating factors are explored in relation to this type of injury.

Key words: agricultural trauma, mortality, power take-off shaft

\section{CASE REPORTS}

\section{Case 1}

A 24-year old male farmer sustained a compound fracture of the second metacarpal and closed fractures of the proximal and middle phalanges of the ring and middle fingers of his left hand with associated soft tissue crush injury due to contact with an unguarded PTO drive. This injury resulted in loss of function of the left hand even after long-term physiotherapy had been completed.

\section{Case 2}

A 45-year old male farmer sustained avulsion of his left index finger at the metacarpophalangeal joint together with a compound fracture of the proximal phalanx of both the thumb and middle finger of the same hand. This injury resulted in limited range of movement of the left thumb and middle finger which was complicated by infection following surgery. This injury occurred when the farmer was changing the drive shaft having removed the guards some time previously for easier access to the linkages.

\section{Case 3}

A 22-year old male farm labourer whilst helping on a neighbour's farm using unfamiliar equipment, caught his long-sleeved shirt in an unguarded PTO device. This resulted in avulsion of his left thumb and index finger at the metacarpophalangeal joints with concommitant closed fractures of his first and second metacarpals. Functional loss in his left hand was severe and further reconstructive surgery was planned.

\section{Case 4}

A 21-year old man who worked as a farm labourer was brought in to hospital following entrapment of 
P. Hyland-McGuire his right arm in an unguarded PTO shaft. His upper limb remained attached by a small posterolateral bridge of musculocutaneous tissue. However, his main axillary neuro-vascular bundle was completely avulsed and consequently amputation of his right upper limb at shoulder joint level was performed. Additionally he sustained fractures of the right second to sixth ribs. He developed post-operative skin necrosis over a small area of his right shoulder joint which was subsequently skin grafted. He was discharged awaiting subsequent arrangements for prosthetic evaluation and management.

\section{Case 5}

A 50-year old man was brought in dead to hospital having been found by his son attached to a stillrotating PTO shaft. His limbs had been completely flailed off during the rotation. The power take-off shaft was unguarded and the farmer had been milling corn with a stationary tractor at the time of the accident.

\section{DISCUSSION}

A PTO is a coupling device which transmits rotational drive from the rear end of a tractor to the diverse range of powered implements that can be attached to it (Fig. 1). Essentially it consists of a telescopic shaft (Fig. 2) with one part of the main shaft sliding inside the other and usually two universal joints (Fig. 3), one near the tractor and one next to the implement attached to the tractor. The universal joints permit bending of the shaft to a certain degree whilst still allowing it to rotate. The telescopic device telescopes in and out as the shaft lengthens and shortens as the implement is lowered or raised from the ground on the hydraulic lift of the tractor. This complexity is also necessary in trailed, powered implements due to the inevitable differential movement of the tractor and trailed implement while turning and negotiating undulations of the ground. New PTO devices are supplied with protective plastic guards which because of the shaft's articulations and telescopic capabilities, are composed of a number of separate parts. Rotation of the guards is prevented by light chains attached to the machine. This arrangement encases the rotating shaft in a non-rotating guard. A fully guarded shaft poses little threat to the user. However, a number of problems arise:

(1) These multi-part guards frequently come off when transferring the drive shaft from one implement to the next. The middle telescopic half-shafts can slide completely out of each other and hence the protective guard commonly slips off and is not replaced. This will result in a bare, rotating shaft with danger of entrapment of the user. Carelessness

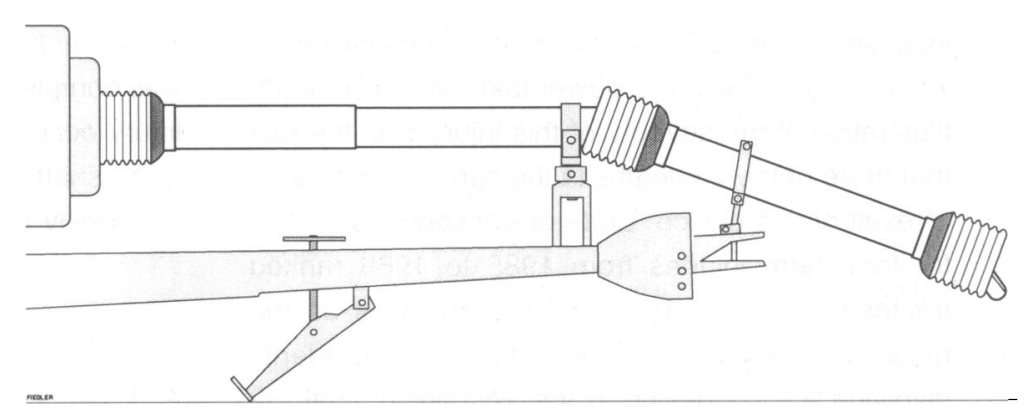

Fig. 1. Diagram illustrating a fully shielded, dedicated power take-off shaft sited above the tow-bar of a trailed, powered implement. The various articulations are necessary to allow continuing rotation of the shaft when turning and negotiating undulations. The outer shields are fixed to prevent rotation hence isolating the inner rotating shaft. Such an arrangement presents little threat to the user.

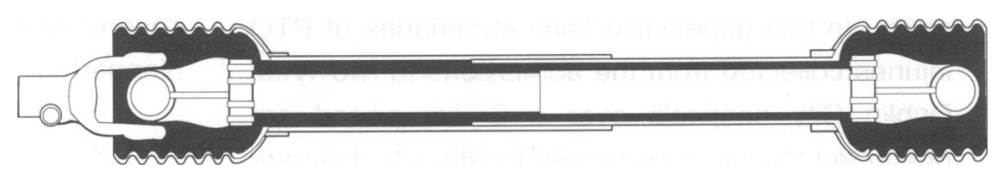

Fig. 2. Diagram illustrating a typical drive shaft showing central telescopic arrangement which allows shortening and lengthening of the device. The outer protective shield also telescopes. Complete separation of the ends is possible and this can lead to a situation where the shields are not replaced. 
Farming accidents involving PTO

devices
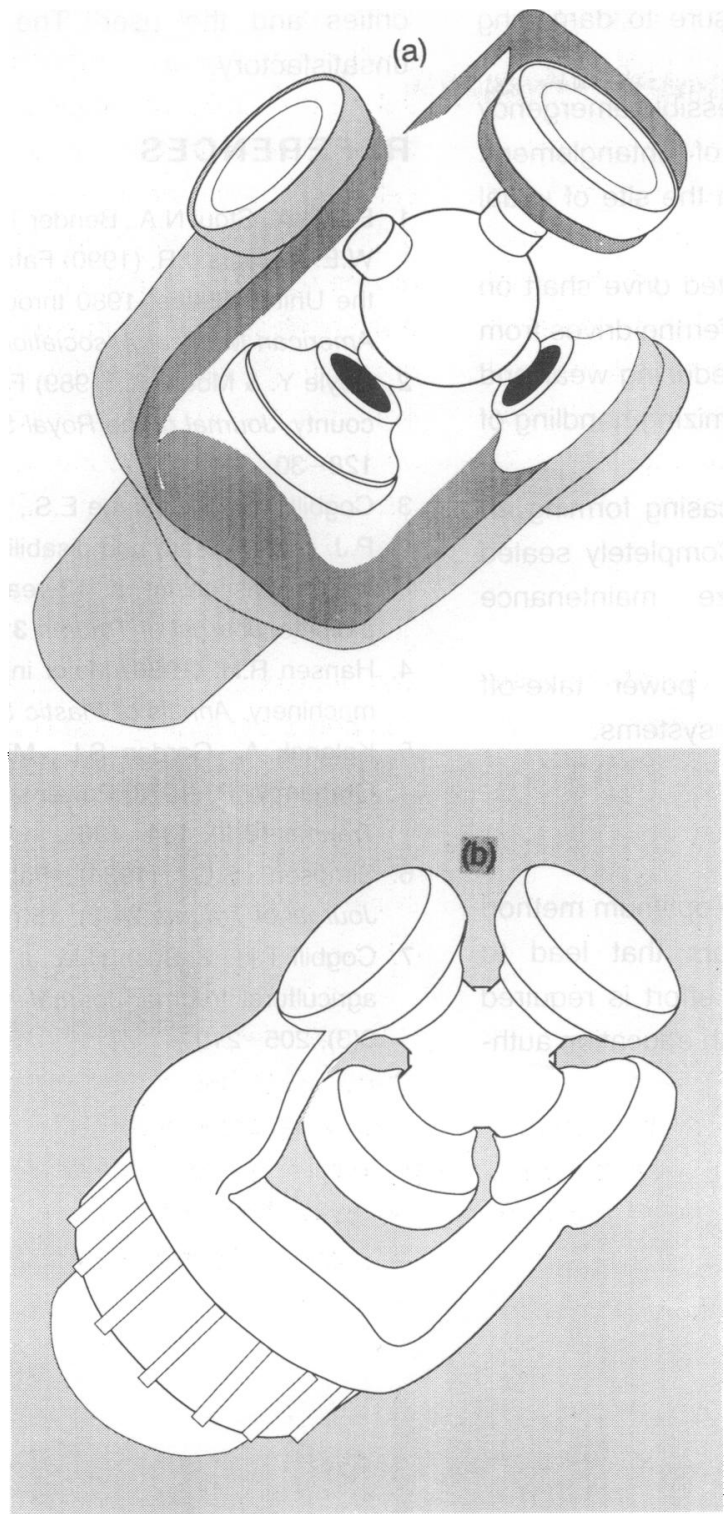

Fig. 3. Diagram showing exploded view (a) and a standard view (b) of a universal joint illustrating its capacity to pivot in all directions. Difficulty arises in effectively shielding this joint while still allowing freedom of movement. As the system is not fully sealed, it must be dismantled for periodic cleaning and greasing. A fully sealed system would reduce the risk of non-replacement or improper replacement of shields by reducing maintenance requirements. The complex contours of this joint can easily gain the initial purchase on clothing which can lead to wrapping around the power take-off device.

and failure to use protective shields have been implicated as the most common cause of farming mishaps. ${ }^{4,6}$

(2) Additionally these guards are the Achilles heel of an otherwise long-lasting and robust device and are subject to deterioration from exposure to ultraviolet light which makes the plastic material brittle and subject to breakage. Hence, it is common to see unguarded older shafts.

(3) Relatively recently independent power takeoff drives the rotation of which is independent of the ground speed of the tractor have been developed. These continue to rotate when the tractor is stationary and have two speed settings of 540 and $1080 \mathrm{rpm}$. Hence it is more likely to contact a rotating shaft when freeing fouled implements or stepping over a rotating shaft in these systems if the drive to the shaft is left engaged. The high rotating speed will result in rapid entanglement with little chance of evasive action.

(4) Farmers traditionally wear non-purpose designed loose garments which greatly increase the likelihood of becoming entangled in rotating shafts. Wrapping of clothing around the shaft is the usual initial event in these accidents. ${ }^{3}$

(5) Modern tractors have large horse-power ratings and an entangled limb is unlikely to stall such a powerful engine. Hence fatalities and avulsion of major parts is a common sequel to entrapment in this situation.

(6) Farmers frequently work alone in remote areas and accidents may not be discovered for many hours if the victim is unconscious or trapped. ${ }^{7}$ Entrapment frequently precludes access to machinery cut-off controls.

\section{CONCLUSIONS}

Currently PTO injuries represent an important cause of death and severe extremity and nerve injuries in the farming community. Most such accidents have significant risk-taking and negligence as precipitating factors. A number of suggestions at primary prevention are as follows.

(1) Health education of farmers regarding the dangers inherent in using PTO. For example, an appropriate advertisement interlude during a popular rural drama series might be most appropriate in reaching the desired audience.

(2) Health education programmes advising the farming community in the use of industrial standard clothing with tight-fitting sleeves and additionally to treat farming as a hazardous industry unsuitable for other members of the public as participators or observers (in one study in Irish General Practice ${ }^{2}$ of all types of farm injuries, children accounted for $16 \%$ of all accident cases).

(3) Improvement of design of PTO guards making them less easy to remove and less prone to deterioration of materials with age. Additionally, garaging 
of equipment reduces the exposure to damaging ultraviolet radiation.

(4) Placement of an easily accessible emergency cut-off near to the usual site of entanglement. Present controls are remote from the site of usual contact.

(5) Using a permanent dedicated drive shaft on each implement rather than transferring drives from one implement to the next thus reducing wear and tear on individual drives and minimizing handling of these dangerous devices.

(6) Encasing drives in metal casing forming an integral part of each machine. Completely sealed devices would also minimize maintenance problems.

(7) Selective replacement of power take-off devices with safer hydraulic drive systems.

\section{SUMMARY}

Primary prevention represents the optimum method of virtually abolishing the factors that lead to this injury scenario. Cooperative effort is required on the part of manufacturers, health education auth- orities and the user. The present situation is unsatisfactory.

\section{REFERENCES}

1. Bell C.A., Stout N.A., Bender T.R., Conroy C.S., Crouse W.E. \& Myers J.R. (1990) Fatal occupational injuries in the United States, 1980 through 1985. Journal of the American Medical Association, 263(22), 3047-3050.

2. Doyle Y. \& Moore A. (1989) Farm accidents in an Irish county. Journal of the Royal Society of Health 109(4), 128-30.

3. Cogbill T.H., Steenlage E.S., Landercasper J. \& Strutt P.J. (1991) Death and disability from agricultural injuries in Wisconsin: a 12-year experience with 739 patients. Journal of Trauma 31(12), 1632-1637.

4. Hansen R.H. (1986) Major injuries due to agricultural machinery. Annals of Plastic Surgery 17(1), 59-64.

5. Kalenak A., Gordon S.L., Miller S.H., Greer R.B. \& Graham W.P. (1978) Power take-off injuries. Journal of Trauma 18(2), 134-136.

6. Simpson S.G. (1984) Farm machinery injuries. Journal of Trauma 24(2), 150-152.

7. Cogbill T.H., \& Bush H.M. Jr (1985) The spectrum of agricultural trauma. Journal of Emergency Medicine 3(3), 205-210. 